"This document is the Accepted Manuscript version of a Published Work that appeared in final form in Org. Lett. 2016, 18, 6042-6045. copyright (C) American Chemical Society after peer review and technical editing by the publisher. To access the final edited and published work see DOI: 10.1021/acs.orglett.6b02981. This article may be used for non-commercial purposes in accordance with the ACS guidelines published at http://pubs.acs.org/page/policy/articlesonrequest/index.html]." 


\title{
Palladium-Catalyzed Stereoselective Formation of Substituted Al- Iylic Thioethers and Sulfones
}

\author{
José Enrique Gómez, ${ }^{\dagger}$ Wusheng Guo, ${ }^{*}, \dagger$ and Arjan W. Kleij*,†,§
}

${ }^{\dagger}$ Institute of Chemical Research of Catalonia (ICIQ), the Barcelona Institute of Science and Technology, Av. Països Catalans 16, 43007 - Tarragona, Spain

§Catalan Institute of Research and Advanced Studies (ICREA), Pg. Lluís Companys 23, 08010 - Barcelona, Spain

Supporting Information Placeholder

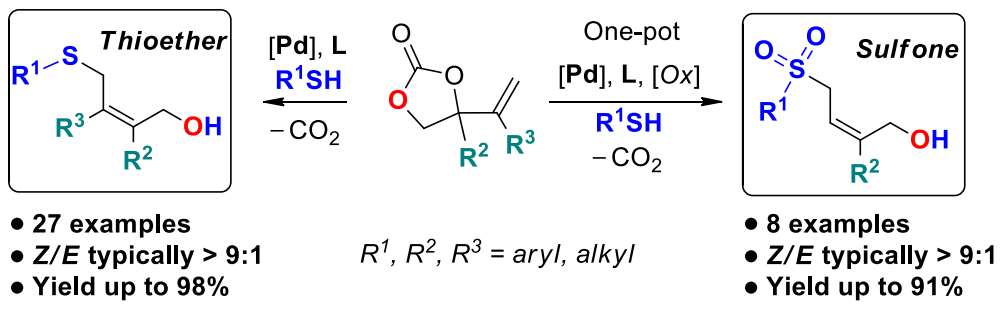

\begin{abstract}
A general method is reported for the stereoselective preparation of highly functionalized allylic thioethers. This protocol is based on a Pd-catalyzed thiolation of modular vinyl cyclic carbonate substrates and features high (Z)-selectivity, good yields, minimal waste, ample product scope and operational simplicity. A one-pot strategy was used towards the stereoselective formation of pharma-relevant allylic sulfones derived from their in situ prepared thioether precursors.
\end{abstract}

Organosulfur compounds such as thioethers ${ }^{1}$ and sulfones ${ }^{2}$ are very important building blocks in synthetic and pharmaceutical chemistry, and their derivatives were representative in around $20 \%$ of the best-selling US pharmaceuticals in $2012 .^{3}$ As a subclass of sulfur-containing compounds, a number of allylic thioethers have been found to be bioactive ${ }^{4}$ and important reaction intermediates, ${ }^{5}$ and continue to attract the interest from various synthetic communities. ${ }^{6,7}$ Effective methodologies for the synthesis of allylic thioether/sulfones and related compounds include allylic substitution, ${ }^{8}$ hydrothiolation of allenes ${ }^{7,9}$ or alkynes, ${ }^{10}$ and $\mathrm{C}-\mathrm{H}$ bond functionalization. ${ }^{11}$ Apart from these catalytic methodologies, also stoichiometric approaches have proven to be effective in this context. ${ }^{12}$ Despite the impressive progress noted in this area, general catalytic methodology for the stereoselective synthesis of highly substituted allylic thioethers (see structure in the blue box of Scheme 1) remains underdeveloped. ${ }^{13} \mathrm{~A}$ recent example of $(Z)$-selective allylic thioether and sulfone synthesis was reported by Breit et al. using hydrothiolation of allenes under Rh catalysis (Scheme 1 , a), ${ }^{7}$ but this approach is limited in substitution diversity around the allylic double bond. A stereoselective construction of multi-functionalized olefin scaffolds represents a rather challenging task in synthetic chemistry. ${ }^{14}$

Our group recently developed a Pd-catalyzed stereoselective methodology for the decarboxylative functionalization of vinyl carbonates towards synthetically useful, highly substituted ( $Z$ )configured allylic amines and 1,4-but-2-ene-diols. ${ }^{15}$ Key to the high $(Z)$ selectivity found in these transformations was the in situ generation of a six-membered palladacycle revealed by DFT calculations (Scheme 1, b). ${ }^{15 \mathrm{~b}}$ We envisaged that, under suitable reaction conditions, the reaction of modular vinyl carbonates and thiol nucleophiles would give access to $(Z)$-allylic thioethers through nucleophilic attack onto the in situ formed Pd-intermediate. Such a manifold would thus offer a practical route towards the challenging stereoselective synthesis of triand even tetra-substituted allylic thioethers and sulfones (upon oxidation) from simple and accessible precursors (Scheme 1, b). (Allylic) sulfone scaffolds are frequently observed in relevant pharmaceutical compounds ${ }^{16}$ and thus their synthesis is of significant importance. ${ }^{17}$

Scheme 1. Different Strategies for Catalytic Stereoselective Synthesis of Allylic Thioethers and Sulfones

(a) Breit et al.

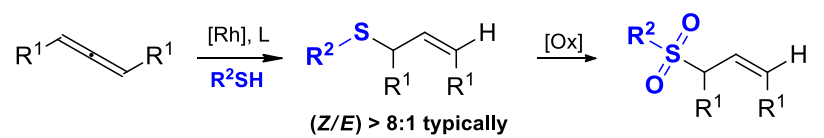

(b) This work:

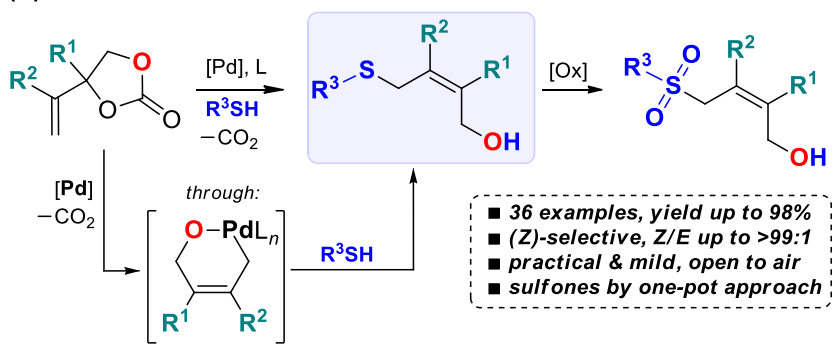


We started our investigations using vinyl carbonate A (Table 1) and thiophenol as a benchmark reaction. Inspired by our previous research, ${ }^{15}$ the combination of the White catalyst precursor $(2.0 \mathrm{~mol} \%)$ and bidentate phosphine L1 (DPEPhos, $5.0 \mathrm{~mol}$ $\%$ ) was first examined at rt (Table 1, entries 1-5). Unfortunately, in different solvents no reaction was observed (DMF, THF, $\mathrm{MeOH}$ and $\left.\mathrm{CH}_{3} \mathrm{CN}\right)$. To our delight, when $\mathrm{Pd}(\mathrm{dba})_{2}$ in $\mathrm{CH}_{3} \mathrm{CN}$ was used, a $16 \%$ yield of allylic thioether 1a $(Z / E=86: 14)$ was noted (Table 1, entry 6). Increasing the temperature (Table 1 , entries 8-9) gave significantly improved yield of 1a of up to $84 \%$ and higher selectivity $(Z / E=92: 8)$.

Table 1. Screening Data for the Optimization of the Reaction Conditions towards Allylic Thioether 1a. ${ }^{a}$

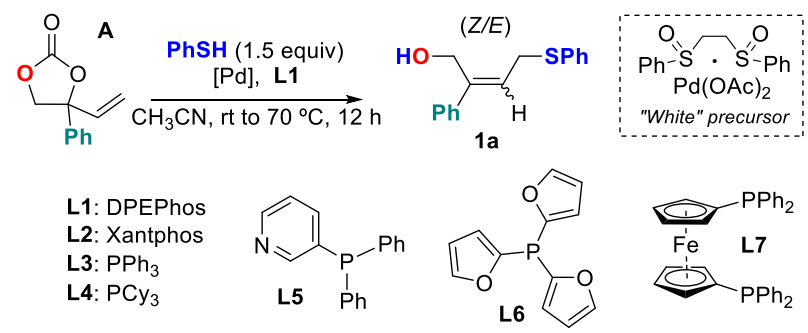

$\begin{array}{cccccc}\text { entry } & {[\mathrm{Pd}]} & \mathrm{L} / \mathrm{solv} & t\left({ }^{\circ} \mathrm{C}\right) & \text { yield }(\%)^{b} & \mathrm{Z}: E^{\mathrm{c}} \\ 1 & \text { "White" } & \mathbf{L 1}, \mathrm{none} & \mathrm{rt} & 0 & - \\ 2 & \text { "White" } & \mathbf{L 1}, \mathrm{DMF} & \mathrm{rt} & 0 & - \\ 3 & \text { "White" } & \mathbf{L 1}, \mathrm{THF} & \mathrm{rt} & 0 & - \\ 4 & \text { "White" } & \mathbf{L 1}, \mathrm{CH}_{3} \mathrm{CN} & \mathrm{rt} & 0 & - \\ 5 & \text { "White" } & \mathbf{L 1}, \mathrm{MeOH} & \text { rt } & 0 & - \\ 6 & \mathrm{Pd}(\mathrm{dba})_{2} & \mathbf{L 1}, \mathrm{CH}_{3} \mathrm{CN} & \text { rt } & 16 & 86: 14 \\ 7 & \mathrm{Pd}(\mathrm{OAc})_{2} & \mathbf{L 1}, \mathrm{CH}_{3} \mathrm{CN} & \text { rt } & 0 & - \\ 8 & \mathrm{Pd}(\mathrm{dba})_{2} & \mathbf{L 1}, \mathrm{CH}_{3} \mathrm{CN} & 50 & 77 & 91: 9 \\ 9 & \mathrm{Pd}(\mathrm{dba})_{2} & \mathbf{L 1}, \mathrm{CH}_{3} \mathrm{CN} & 70 & 84 & 92: 8 \\ 10^{d} & \mathrm{Pd}(\mathrm{dba})_{2} & \mathbf{L 1}, \mathrm{CH}_{3} \mathrm{CN} & 70 & 91 & 94: 6 \\ 11 & \mathrm{Pd}(\mathrm{dba})_{2} & \mathbf{L 2}, \mathrm{CH}_{3} \mathrm{CN} & 70 & 83 & 94: 6 \\ 12 & \mathrm{Pd}(\mathrm{dba})_{2} & \mathbf{L 3}, \mathrm{CH}_{3} \mathrm{CN} & 70 & 0 & - \\ 13 & \mathrm{Pd}(\mathrm{dba})_{2} & \mathbf{L 4}, \mathrm{CH}_{3} \mathrm{CN} & 70 & 0 & - \\ 14 & \mathrm{Pd}(\mathrm{dba})_{2} & \mathbf{L 5}, \mathrm{CH}_{3} \mathrm{CN} & 70 & 0 & - \\ 15 & \mathrm{Pd}(\mathrm{dba})_{2} & \mathbf{L 6}, \mathrm{CH}_{3} \mathrm{CN} & 70 & 0 & - \\ 16 & \mathrm{Pd}(\mathrm{dba})_{2} & \mathbf{L 7}, \mathrm{CH}_{3} \mathrm{CN} & 70 & 0 & - \\ 17^{e} & \mathrm{Pd}(\mathrm{dba})_{2} & \mathbf{L 1}, \mathrm{CH}_{3} \mathrm{CN} & 70 & 73 & 90: 10 \\ 18^{f} & \mathrm{Pd}(\mathrm{dba})_{2} & \mathbf{L 1}, \mathrm{CH}_{3} \mathrm{CN} & 70 & 92 & 91: 9\end{array}$

${ }^{a}$ Reaction conditions unless otherwise stated: carbonate substrate $(0.20$ mmol), thiophenol (1.5 equiv), solvent $(0.20 \mathrm{~mL})$, catalyst $(2.0 \mathrm{~mol} \%), \mathbf{L}$ $(5.0 \mathrm{~mol} \%)$, open to air, $12 \mathrm{~h} .{ }^{b} \mathrm{NMR}$ yield using toluene as an internal standard. ${ }^{c}$ Based on ${ }^{1} \mathrm{H}$ NMR integration. ${ }^{d}[\mathrm{Pd}]=3.0 \mathrm{~mol} \% .{ }^{e}[\mathrm{Pd}]=3.0$ mol $\%$, thiophenol $\left(1.2\right.$ equiv). ${ }^{f}[\mathrm{Pd}]=3.0 \mathrm{~mol} \%$, thiophenol $(0.20 \mathrm{mmol})$ and carbonate substrate $(0.22 \mathrm{mmol})$.

The catalysis was further enhanced with a higher Pd loading (3.0 mol \%; $91 \%$ yield, $Z / E=94: 6$ : Table 1 , entry 10 ). Other phosphine ligands $\mathbf{L} \mathbf{2}-\mathbf{L} 7$ were also tested but proved to be less productive (Table 1, entries 11-16), and a lower thiophenol amount also resulted in erosion of the yield of $\mathbf{1 a}$ (1.2 equiv, Table 1, entry 17). Under the optimized conditions, the use of excess of carbonate gave fairly similar results (Table 1, entry $18 ; 92 \%$ yield, $Z / E=91: 9)$. Thus, the best conditions towards the formation of allylic thioether $(Z)-\mathbf{1 a}$ were the use of $\mathrm{Pd}(\mathrm{dba})_{2}(3.0 \mathrm{~mol} \%), \mathbf{L 1}(5.0 \mathrm{~mol} \%)$ in $\mathrm{CH}_{3} \mathrm{CN}$ at $70{ }^{\circ} \mathrm{C}$ (Table
1 , entry 10). It is worth noting that no special precautions or base additives ${ }^{18}$ were required making the present protocol highly attractive from a practical point of view.

Table 2. Investigated Scope in Thiol Partners to Produce Allylic Thioethers 1a-11. ${ }^{a}$

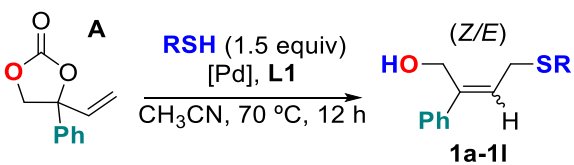

\begin{tabular}{|c|c|c|c|c|}
\hline entry & $\mathrm{R}$ & product & yield $(\%)^{b}$ & $Z / E$ \\
\hline 1 & $\mathrm{C}_{6} \mathrm{H}_{5}$ & 1a & 90 & $94: 6$ \\
\hline 2 & 4-Me- $\mathrm{C}_{6} \mathrm{H}_{4}$ & 1b & 73 & $92: 8$ \\
\hline 3 & 2-Me- $\mathrm{C}_{6} \mathrm{H}_{4}$ & 1c & 93 & $92: 8$ \\
\hline $4^{c}$ & 4- $\mathrm{CF}_{3}-\mathrm{C}_{6} \mathrm{H}_{4}$ & 1d & 70 & $83: 17$ \\
\hline $5^{c}$ & $4-\mathrm{Br}-\mathrm{C}_{6} \mathrm{H}_{4}$ & 1e & 76 & $80: 20$ \\
\hline 6 & $3-\mathrm{Me}-\mathrm{C}_{6} \mathrm{H}_{4}$ & 1f & 95 & $90: 10$ \\
\hline 7 & $4-\mathrm{MeO}-\mathrm{C}_{6} \mathrm{H}_{4}$ & $1 \mathrm{~g}$ & 83 & $93: 7$ \\
\hline $8^{c}$ & 4- $\mathrm{COOH}-\mathrm{C}_{6} \mathrm{H}_{4}$ & 1h & 98 & $91: 9$ \\
\hline 9 & 2-pyridyl & $\mathbf{1 i}$ & 93 & $>99: 1$ \\
\hline $10^{c}$ & 4-HO- $\mathrm{C}_{6} \mathrm{H}_{4}$ & $1 \mathbf{j}$ & 87 & $91: 9$ \\
\hline $11^{c}$ & Adamantyl & $1 \mathrm{k}$ & 98 & $>99: 1$ \\
\hline $12^{c}$ & Benzyl & 11 & 50 & $92: 8$ \\
\hline
\end{tabular}

${ }^{a}$ Reaction conditions unless otherwise stated: carbonate substrate $(0.20$ mmol), thiol (1.5 equiv), $\mathrm{CH}_{3} \mathrm{CN}(0.20 \mathrm{~mL}), \mathrm{Pd}(\mathrm{dba})_{2}(3.0 \mathrm{~mol} \%), \mathbf{L 1}(5.0$ mol \%), $70{ }^{\circ} \mathrm{C}, 12 \mathrm{~h} ;{ }^{b}$ Isolated yield. ${ }^{c}$ Thiol $(0.20 \mathrm{mmol})$, carbonate substrate (0.22 mmol).

With the optimized conditions in hand, we then systematically varied the nature of both reaction partners, and first the scope in thiols was examined (Table 2). Generally, the decarboxylative thiolation approach proceeded with high stereoselectivity providing the allylic thioethers $\mathbf{1 a - 1 1}$ in good yields and $Z / E$ ratios typically being $>90: 10$. Both the presence of electron-withdrawing $(\mathbf{1 d}, \mathbf{1 e}, \mathbf{1 h}$ and $\mathbf{1 i})$ and -donating groups $(\mathbf{1 b}$, 1c, $1 \mathbf{f}, \mathbf{1 g}, \mathbf{1 j}$ ) in the aryl thiols is tolerated, and para-meta- and ortho-substitutions (Table 2, entries 2, 3 and 6) are endorsed. Deactivated thiophenols also showed sufficient reactivity ( $c f$., synthesis of 1d and $\mathbf{1 h}$ ). Variation of the thiol partners allows to include synthetically useful aryl-halides (1e), benzoic acid (1h), pyridyl (1i) and phenoxy (1j) groups. Apart from aryl thiols, alkyl thiols also proved to be feasible substrates leading to their respective allylic thioethers in high stereoselectivty (1k and 11, $Z / E>92: 8)$. In some cases, the catalytic procedure was optimized by using a slight excess of vinyl carbonate substrate. The $(Z)$ configuration of the major isomer in all cases was supported by ${ }^{1} \mathrm{H}$ NOESY (Supporting Information, SI), and for 1a also by X-ray analysis (see SI).

Subsequently, the vinyl carbonate reaction partner was varied (Table 3) giving access to a wider range of highly functionalized allylic thioethers $\mathbf{2 a}-\mathbf{2 l}$ in moderate to excellent yields (up to $97 \%$ ) with high stereocontrol in most cases (Z/E ratios of at least $>80: 20$ ). Both aryl and alkyl substituents in the carbonate reagent (Table 3, "R") were tolerated. Different functionalities such as benzoic esters, aryl nitrile and furyl groups (2e, $\mathbf{2 f}$ and $2 \mathbf{i})$ can be readily introduced further amplifying the product diversity. Upon using more sterically demanding vinyl carbonates 
that incorporate naphthyl- or cyclohexyl substituents, the catalytic procedure was less productive (2g and $\mathbf{2 j} ; 51 \%$ and $48 \%$ yield, respectively). In the case of product $\mathbf{2 l}$ we observed the formation of a branched allylic thioether which affected the yield of the linear derivative (see SI for details). The observed lower $Z / E$ ratios observed for $\mathbf{2 f}$ and $\mathbf{2 k}$ (Table 3 ) may be the result of the oxa-palladacycle (see Scheme $1 \mathrm{~b}$ ) being in equilibrium with a non-cyclic intermediate at $70^{\circ} \mathrm{C}$. The carbonate $\mathrm{R}$-substituent in the acyclic species can affect the olefin geometry prior to attack of the thiol nucleophile through possible $\pi-\sigma-\pi$ alkene isomerization. ${ }^{19}$ A higher tendency to form such an acyclic Pd-intermediate causes loss in stereocontrol.

Table 3. Investigated Scope in Vinyl Carbonate Partners to Produce Allylic Thioethers 2a-2l ${ }^{a}$

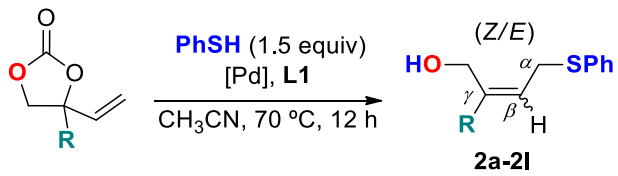

\begin{tabular}{|c|c|c|c|c|}
\hline entry & $\mathrm{R}$ & product & yield $(\%)^{b}$ & $Z / E$ \\
\hline 1 & 4-Me- $\mathrm{C}_{6} \mathrm{H}_{4}$ & $2 a$ & 70 & $94: 6$ \\
\hline 2 & $4-\mathrm{F}-\mathrm{C}_{6} \mathrm{H}_{4}$ & $2 \mathbf{b}$ & 84 & $83: 17$ \\
\hline 3 & $4-\mathrm{Br}-\mathrm{C}_{6} \mathrm{H}_{4}$ & $2 \mathrm{c}$ & 88 & $87: 13$ \\
\hline 4 & 4- $\mathrm{Ph}-\mathrm{C}_{6} \mathrm{H}_{4}$ & $2 d$ & 97 & $94: 6$ \\
\hline 5 & $4-\mathrm{CO}_{2} \mathrm{Me}-\mathrm{C}_{6} \mathrm{H}_{4}$ & $2 e$ & 80 & $84: 16$ \\
\hline 6 & $4-\mathrm{CN}-\mathrm{C}_{6} \mathrm{H}_{4}$ & $2 f$ & 91 & $67: 33$ \\
\hline 7 & 2-naphthyl & $2 \mathrm{~g}$ & 51 & $89: 11$ \\
\hline 8 & $3-\mathrm{Cl}-\mathrm{C}_{6} \mathrm{H}_{4}$ & $2 \mathrm{~h}$ & 71 & $80: 20$ \\
\hline 9 & 2-furyl & $2 \mathbf{i}$ & 99 & $>99: 1$ \\
\hline $10^{c}$ & Cy & $2 \mathbf{j}$ & 48 & $84: 16$ \\
\hline $11^{c}$ & $\mathrm{C}_{10} \mathrm{H}_{21}$ & $2 k$ & 87 & $70: 30$ \\
\hline 12 & $\mathrm{Me}$ & 21 & $40^{d}$ & $80: 20$ \\
\hline
\end{tabular}

${ }^{a}$ Reaction conditions unless otherwise stated: carbonate substrate $(0.20$ mmol), thiophenol (1.5 equiv), $\mathrm{CH}_{3} \mathrm{CN}(0.20 \mathrm{~mL}), \mathrm{Pd}(\mathrm{dba})_{2}(3.0 \mathrm{~mol} \%)$, L1 (5.0 mol \%), $70{ }^{\circ} \mathrm{C}, 12 \mathrm{~h} .{ }^{b}$ Isolated yield. ${ }^{c}$ Thiophenol $(0.20 \mathrm{mmol})$, carbonate substrate $(0.22 \mathrm{mmol}) .{ }^{d}$ Branched product $(30 \%)$ also formed.

In order to further challenge the newly developed catalytic protocol for stereoselective allylic thioether formation, the synthesis of elusive tetra-substituted derivatives was attempted and the results are listed in Table 4. To our delight, the installation of both alkyl- and aryl-substituents $\left(\mathrm{R}^{2}=\mathrm{Ph}, \mathrm{Me}\right)$ at the $\beta$-position of the allylic scaffold is feasible while maintaining excellent stereoselectiviy (Table 4, entries 1 and 2: 3a and 3b, Z/E > 94:6). However, the preparation of $\alpha$-functionalized allylic thioethers, derived from internal olefin substrates, failed under these conditions probably because of steric reasons (see SI for details). Other combinations of $\mathrm{R}^{1}$ and $\mathrm{R}^{2}$ were then also probed (cf., synthesis of $\mathbf{3 c}$ and $\mathbf{3 d}$ ) and gave the targeted allylic thioethers in high to excellent stereoselectivity.

We then set out to develop a one-pot strategy towards the stereoselective synthesis of highly substituted allylic sulfones by combining the Pd-catalyzed allylic thioether formation and in situ oxidation. Various conditions were tested using vinyl carbonate $\mathbf{A}$ and thiophenol as a model reaction (see SI for more details). We were pleased to find that a combination of $\left(\mathrm{NH}_{4}\right)_{6} \mathrm{Mo}_{7} \mathrm{O}_{21} \cdot 4 \mathrm{H}_{2} \mathrm{O}$ and $\mathrm{H}_{2} \mathrm{O}_{2}$ (after initial and in situ formation of allylic thioether 1a) gave $90 \%$ isolated yield of sulfone product $\mathbf{4 a}$ (Table 5, entry 1) with excellent stereocontrol
$(Z / E=94: 6) .{ }^{20}$ This one-pot strategy was then utilized to prepare different, highly functionalized sulfones (Table 5, entries $2-8)$. Gratifyingly the oxidation step did not interfere with the presence of other (functional) groups under these conditions including benzyl (4d), pyridyl (4e), methylester (4f), halide (4g) and in all cases primary alcohol and internal alkene groups. The same level of stereoselectivity was found in the sulfone synthesis, and generally good to excellent yields for $\mathbf{4 a}-\mathbf{4 h}$ were obtained. X-ray analysis of $\mathbf{4 a}$ unambiguously confirmed the ( $Z$ )configuration of this tri-substituted allylic sulfone (see SI).

Table 4. Preparation of Elusive Tetra-Substituted Thioethers $3 \mathbf{a}-3 \mathbf{d}^{a}$

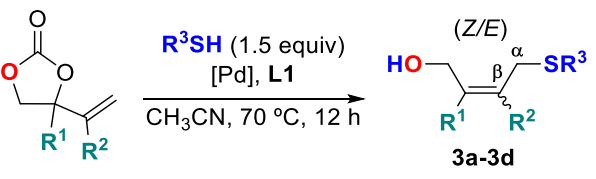

\begin{tabular}{ccccccc}
$\begin{array}{c}\text { en- } \\
\text { try }\end{array}$ & $\mathrm{R}^{1}$ & $\mathrm{R}^{2}$ & $\mathrm{R}^{3}$ & $\begin{array}{c}\text { prod- } \\
\text { uct }\end{array}$ & yield $(\%)^{b}$ & $\mathrm{Z} / E$ \\
\hline 1 & $p-\mathrm{Me}-\mathrm{C}_{6} \mathrm{H}_{4}$ & $\mathrm{Ph}$ & $\mathrm{Ph}$ & $\mathbf{3 a}$ & 48 & $>99: 1$ \\
2 & $\mathrm{Ph}$ & $\mathrm{Me}$ & $\mathrm{Ph}$ & $\mathbf{3 b}$ & 62 & $94: 6$ \\
3 & $\mathrm{Ph}$ & $\mathrm{Me}$ & $4-\mathrm{MeO}^{-} \mathrm{C}_{6} \mathrm{H}_{4}$ & $\mathbf{3 c}$ & 65 & $98: 2$ \\
4 & $\mathrm{Ph}$ & $\mathrm{Me}$ & $2-\mathrm{Me}^{-} \mathrm{C}_{6} \mathrm{H}_{4}$ & $\mathbf{3 d}$ & 37 & $90: 10$
\end{tabular}

${ }^{a}$ Reaction conditions unless otherwise stated: carbonate substrate $(0.20$ mmol), thiophenol (1.5 equiv), $\mathrm{CH}_{3} \mathrm{CN}(0.20 \mathrm{~mL}), \mathrm{Pd}(\mathrm{dba})_{2}(3.0 \mathrm{~mol} \%)$, L1 (5.0 mol \%), $70{ }^{\circ} \mathrm{C}, 12$ h. ${ }^{b}$ Isolated yield.

Table 5. One-Pot Synthesis of Highly Substituted Sulfones ${ }^{a}$

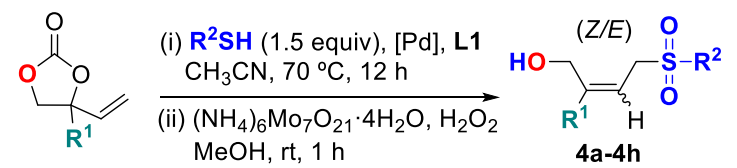

\begin{tabular}{cccccc} 
entry & $\mathrm{R}^{1}$ & $\mathrm{R}^{2}$ & product & yield $(\%)^{b}$ & Z/E \\
\hline 1 & $\mathrm{Ph}$ & $\mathrm{Ph}$ & $\mathbf{4 a}$ & 90 & $94: 6$ \\
2 & $\mathrm{Ph}$ & $4-\mathrm{MeO}^{-} \mathrm{C}_{6} \mathrm{H}_{4}$ & $\mathbf{4 b}$ & 83 & $93: 7$ \\
3 & $\mathrm{Ph}$ & $3-{\mathrm{Me}-\mathrm{C}_{6} \mathrm{H}_{4}}$ & $\mathbf{4 c}$ & 89 & $90: 10$ \\
4 & $\mathrm{Ph}$ & Benzyl & $\mathbf{4 d}$ & 48 & $91: 9$ \\
$5^{c}$ & $\mathrm{Ph}$ & $2-\mathrm{pyridyl}$ & $\mathbf{4 e}$ & 91 & $87: 13$ \\
6 & $4-\mathrm{CO}_{2} \mathrm{Me}-\mathrm{C}_{6} \mathrm{H}_{4}$ & $\mathrm{Ph}$ & $\mathbf{4 f}$ & 76 & $84: 16$ \\
7 & $4-\mathrm{F}_{-} \mathrm{C}_{6} \mathrm{H}_{4}$ & $\mathrm{Ph}$ & $\mathbf{4 g}$ & 77 & $93: 7$ \\
8 & $4-\mathrm{Me}_{4} \mathrm{C}_{6} \mathrm{H}_{4}$ & $\mathrm{Ph}$ & $\mathbf{4 h}$ & 72 & $93: 7$
\end{tabular}

${ }^{a}$ Reaction conditions: (i) carbonate substrate $(0.20 \mathrm{mmol})$, thiol (1.5 equiv), $\mathrm{CH}_{3} \mathrm{CN}(0.20 \mathrm{~mL}), \mathrm{Pd}(\mathrm{dba})_{2}(3.0 \mathrm{~mol} \%), \mathbf{L 1}(5.0 \mathrm{~mol} \%), 70{ }^{\circ} \mathrm{C}, 12 \mathrm{~h}$; (ii) $\left(\mathrm{NH}_{4}\right)_{6} \mathrm{Mo}_{7} \mathrm{O}_{21} \cdot 4 \mathrm{H}_{2} \mathrm{O}, \mathrm{H}_{2} \mathrm{O}_{2}$ (4 equiv, 30 wt $\%$ in $\mathrm{H}_{2} \mathrm{O}$ ), $\mathrm{MeOH}(0.20 \mathrm{~mL}$ ), rt, $1 \mathrm{~h}$; X-ray structure measured for sulfone $(Z)-\mathbf{4 a}$, see SI. ${ }^{b}$ Isolated yield. ${ }^{c}$ Thiol $(0.20 \mathrm{mmol})$, carbonate substrate $(0.22 \mathrm{mmol})$.

In summary, we herein report a general catalytic method for the $(Z)$-selective preparation of a diverse series of highly functionalized and substituted allylic thioethers and sulfones. This methodology is based on a Pd-catalyzed decarboxylative functionalization of readily available and modular vinyl cyclic carbonates, and features minimal waste release, wide scope and operationally simplicity. Based on our previous mechanistic investigations, ${ }^{15 \mathrm{~b}}$ the $(Z)$-selectivity in the present catalytic proto$\mathrm{col}$ is ascribed to a nucleophilic attack of the thiol reagent onto 
an in situ generated ( $Z$ )-configured six-membered palladacycle that guides the stereoselective course of the developed process for the $(Z)$ allylic thioethers.

\section{ASSOCIATED CONTENT}

\section{Supporting Information}

Experimental details and copies of relevant NMR and IR spectra for all new products, $\mathrm{X}$-ray data in cif format. This material is available free of charge via the Internet at http://pubs.acs.org.

\section{AUTHOR INFORMATION}

\section{Corresponding Author}

*wguo@iciq.es

*akleij@iciq.es

\section{Notes}

The authors declare no competing financial interest.

\section{ACKNOWLEDGMENT}

We thank ICIQ, ICREA, and the Spanish Ministerio de Economía y Competitividad (MINECO) through projects CTQ-2014-60419$\mathrm{R}$, and the Severo Ochoa Excellence Accreditation 2014-2018 through project SEV-2013-0319. Eduardo C. Escudero-Adán and Dr. Eddy Martin (ICIQ) ${ }^{\dagger}$ are acknowledged for the X-ray analysis of compounds 1a and 4a. J.E.G. acknowledges MINECO and ICIQ for a Severo Ochoa/FPI pre-doctoral fellowship. W.G thanks the Cellex foundation for a postdoctoral fellowship.

\section{REFERENCES}

(1) For general reviews: (a) Mellah, M.; Voituriez, A.; Schulz, E. Chem. Rev. 2007, 107, 5133. (b) Kondo, T.; Mitsudo, T. Chem. Rev. 2000, 100, 3205. (c) Beletskaya, I. P.; Ananikov, V. P. Chem. Rev. 2011, 111, 1596. (d) Castarlenas, R.; Giuseppe, A. D.; Pérez-Torrente, J. J.; Oro, L. A. Angew. Chem. Int. Ed. 2013, 52, 211. (e) McReynolds, M. D.; Dougherty, J. M.; Hanson, P. R. Chem. Rev. 2004, 104, 2239. (e) Ilardi, E. A.; Vitaku, E.; Njardarson, J. T. J. Med. Chem. 2014, 57, 2832.

(2) For reviews: (a) Koschker, P.; Breit, B. Acc. Chem. Res. 2016, 49, 1524; also please see ref 1e. Some recent and/or relevant examples of sulfone synthesis: (b) Deeming, A. S.; Russell, C. J.; Willis, M. C. Angew. Chem. Int. Ed. 2015, 55, 747. (c) Huang, Z.; Lu, Q.; Liu, Y.; Liu, D.; Zhang, J.; Lei, A. Org. Lett. 2016, 18, 3940. (d) Dvorak, C. A.; Schmitz, W. D.; Poon, D. J.; Pryde, D. C.; Lawson, J. P.; Amos, R. A.; Meyers, A. I. Angew. Chem. Int. Ed. 2000, 39, 1664. (e) Szilágyi, Á.; Fenyvesi, F.; Mayercsik, O.; Pelyvás, I. S.; Bácskay, I.; Fehér, P.; Váradi, J.; Vecsernyés, M.; Herczegh, P. J. Med. Chem. 2006, 49, 5626.

(3) McGrath, N. A.; Brichacek, M.; Njardarson, J. T. J. Chem. Ed. 2010, 87, 1348.

(4) (a) Sumiyoshi, H.; Wargovich, M. J. Cancer Res. 1990, 50, 5084. (b) Arora, A.; Siddiqui, I. A.; Shukla, Y. Mol. Cancer Ther. 2004, 3, 1459. (c) Arunkumar, A.; Vijayababu, M. R.; Venkataraman, P.; Senthilkumar, K.; Arunakaran, J. Biol. Pharm. Bull. 2006, 29, 375.

(5) (a) Lin, Y. A.; Chalker, J. M.; Floyd, N.; Bernardes, G. J. L.; Davis, B. G. J. Am. Chem. Soc. 2008, 130, 9642; (b) Liu, T.; Zhao, X.; Lu, L.; Cohen, T. Org. Lett. 2009, 11, 4576. (c) Barluenga, S.; Lopez, P.; Moulin, E.; Winssinger, N. Angew. Chem. Int. Ed. 2004, 43, 3467. (d) Engstrom, K. M.; Mendoza, M. R.; Navarro-Villalobos, M.; Gin, D. Y. Angew. Chem. Int. Ed. 2001, 40, 1128

(6) (a) Kondo, T.; Morisaki, Y.; Uenoyama, S.; Wada, K.; Mitsudo, T. J. Am. Chem. Soc. 1999, 121, 8657. (b) Herkert, L.; Green, S. L. J.; Barker, G.; Johnson, D. G.; Young, P. C.; Macgregor, S. A.; Lee, A.-
L. Chem. Eur. J. 2014, 20, 11540. (c) Roggen, M.; Carreira, E. M. Angew. Chem. Int. Ed. 2012, 51, 8652. (d) Tanaka, S.; Pradhan, P. K.; Maegawa, Y.; Kitamura, M. Chem. Commun. 2010, 46, 3996. (e) Gao, N.; Zheng, S.; Yang, W.; Zhao, X. Org. Lett. 2011, 13, 1514. (f) Sun, J.; Fu, G. C. J. Am. Chem. Soc. 2010, 132, 4568. (g) Fujiwara, Y.; Sun J.; Fu, G. C. Chem. Sci. 2011, 2, 2196. (h) Yatsumonji, Y.; Ishida, Y.; Tsubouchi, A.; Takeda, T. Org. Lett. 2007, 9, 4603.

(7) Pritzius, A. B.; Breit, B. Angew. Chem. Int. Ed. 2015, 54, 15818.

(8) For some examples see: (a) Trost, B. M.; Organ, M. G.; O'Doherty, G. A. J. Am. Chem. Soc. 1995, 117, 9662. (b) Wu, X.-S.; Chen, Y.; Li, M.-B.; Zhou, M.-G.; Tian, S. K. J. Am. Chem. Soc. 2012 134, 14694. (c) Jegelka, M.; Plietker, B. Org. Lett. 2009, 11, 3462.

(9) For relevant examples see: (a) Pritzius, A. B.; Breit, B. Angew. Chem. Int. Ed. 2015, 54, 3121. See also ref 7. For related hydrothiocarbonylation refer to: (b) Xiao, W.-J.; Vasapollo, G.; Alper, H. J. Org. Chem. 1998, 63, 2609. (c) Xiao, W.-J.; Alper, H. J. Org. Chem. 1999, 64, 9646.

(10) For selected examples see: (a) Cao, C.; Fraser, L. R.; Love, J. Am. Chem. Soc. 2005, 127, 17614. (b) Xu, K.; Khakyzadeh, V.; Bury, T.; Breit, B. J. Am. Chem. Soc. 2014, 136, 16124. (c) Riduan, S. N.; Ying, J. Y.; Zhang, Y. Org. Lett. 2012, 14, 1780. (d) Yang, Y.; Rioux, R. M. Green Chem. 2014, 16, 3916. (e) Kondoh, A.; Takami, K.; Yorimitsu, H.; Oshima, K. J. Org. Chem. 2005, 70, 6468. (f) Ananikov, V. P.; Malyshev, D. A.; Beletskaya, I. P.; Aleksandrov, G. G.; Eremenko, I. L. Adv. Synth. Catal. 2005, 347, 1993.

(11) Rao, W.-H.; Zhan, B.-B.; Chen, K.; Ling, P.-X.; Zhang, Z.-Z.; Shi, B.-F. Org. Lett. 2015, 17, 3552.

(12) (a) Reddy, L. R.; Hu, B.; Prashad, M.; Prasad, K. Angew. Chem. Int. Ed. 2009, 48, 172. (b) Examples of syntheses please see: (a) Chu, X.-Q.; Meng, H.; Xu, X.-P.; Ji, S.-J. Chem. Eur. J. 2015, 21, 11359. (c) Ando, K.; Wada, T.; Okumura, M.; Sumida, H. Org. Lett. 2015, 17, 6026.

(13) Only a few non-catalytic methods are known though with limited product diversity: (a) Das, B.; Chowdhury, N.; Damodar, K.; Banerjee, J. Chem. Pharm. Bull. 2007, 55, 1274. (b) Karnakar, K.; Ramesh, K.; Murthy, S. N.; Nageswar, Y. V. D. Helv. Chim. Acta 2013, 96, 2276. (c) Liu, Y.; Xu, X.; Zheng, H.; Xu, Z.; Zhang, Y. Synlett 2006, 571.

(14) Flynn, A. B.; Ogilvie, W. W. Chem. Rev. 2007, 107, 4698.

(15) (a) Guo, W.; Martínez-Rodríguez, L.; Martin, E.; EscuderoAdán, E. C.; Kleij, A. W. Angew. Chem. Int. Ed. 2016, 55, 11037. (b) Guo, W.; Martínez-Rodríguez, L.; Kuniyil, R.; Martin, E.; EscuderoAdán, E. C.; Maseras, F.; Kleij, A. W. J. Am. Chem. Soc. 2016, 138, 11970.

(16) For applications of (allylic) sulfones in pharmaceutical compounds: (a) Chen, X.; Hussain, S.; Parveen, S.; Zhang, S.; Yang, Y.; Zhu, C. Curr. Med. Chem. 2012, 19, 3578. (b) Reck, F.; Zhou, F.; Girardot, M.; Kern, G.; Eyermann, C. J.; Hales, N. J.; Ramsay, R. R.; Gravestock, M. B. J. Med. Chem. 2005, 48, 499. (c) El-Awa, A.; Noshi, M. N.; Mollat du Jourdin, X.; Fuchs, P. L. Chem. Rev. 2009, 109, 2315. (d) Alba, A.-N. R.; Companyó, X.; Rios, R. Chem. Soc. Rev. 2010, 39, 2018

(17) (a) Ueda, M.; Hartwig, J. F. Org. Lett. 2010, 12, 92. (b) Kabalka, G. W.; Venkataiah, B.; Dong, G. Tetrahedron Lett. 2003, 44, 4673. (c) Chandrasekhar, S.; Saritha, B.; Jagadeshwer, V.; Narsihmulu, C.; Vijay, D.; Sarma, G. D.; Jagadeesh, B. Tetrahedron Lett. 2006, 47, 2981. (d) Karnakar, K.; Shankar, J.; Murthy, S. N.; Nageswar, Y. V. D. Helv. Chim. Acta 2011, 94, 875. See also refs 8b-c, 10b and 12a.

(18) Addition of base may lead to competitive 1,2-diol or carbamate formation: (a) Guo, W.; Gónzalez-Fabra, J.; Bandeira, N. A. G.; Bo, C.; Kleij, A. W. Angew. Chem. Int. Ed. 2015, 54, 11686. (b) Laserna, V.; Fiorani, G.; Whiteoak, C. J.; Martin, E.; Escudero-Adán, E. C.; Kleij, A. W. Angew. Chem. Int. Ed. 2014, 53, 10416.

(19) Trost, B. M.; Machacek, M. R.; Aponick, A. Acc. Chem. Res 2006, 39, 747.

(20) A previously reported oxidation procedure was used, see: Jeyakumar, K.; Chakravarthy, D. R.; Chand, D. K. Catal. Commun. 2009, 10,1948 . 